\section{Case Reports in Acute Medicine}

Case Rep Acute Med 2020;3:35-39

DOI: $10.1159 / 000508530$

Published online: June 25, 2020 (c) 2020 The Author(s)

Published by S. Karger AG, Basel www.karger.com/cra

This article is licensed under the Creative Commons Attribution-NonCommercial 4.0 International License (CC BY-NC) (http://www.karger.com/Services/OpenAccessLicense). Usage and distribution for commercial purposes requires written permission.

\title{
Spontaneous Tuberculosis-Associated Tension Pneumothorax: A Case Report and Literature Review
}

\author{
Aditya Doni Pradana \\ Department of Emergency Services, Kendal Islamic Hospital, Kendal, Indonesia
}

\section{Keywords}

Acuity - Pulmonary tuberculosis - Tension pneumothorax - Needle decompression . Emergency management

\begin{abstract}
Secondary spontaneous pneumothorax (SSP) is one of the major complications of pulmonary tuberculosis (TB), and it can be a life-threatening condition if it progresses to tension pneumothorax. A correct initial assessment and prompt intervention will prevent a hemodynamic deterioration in tension pneumothorax. Needle decompression followed by large-bore chest tube insertion is usually required in the management of SSP. We present a case of spontaneous TB-associated tension pneumothorax in a young adult which resolved with needle decompression without chest tube insertion.

(c) 2020 The Author(s)

Published by S. Karger AG, Basel
\end{abstract}

\section{Introduction}

Secondary spontaneous pneumothorax (SSP) is one of the major complications of pulmonary tuberculosis (TB), and it can be a life-threatening condition if it progresses to tension pneumothorax [1]. The incidence of SSP in pulmonary TB was reported to be 1.3-5\% [2]. Correct initial assessment and prompt intervention will prevent a hemodynamic deterioration in tension pneumothorax. The treatment approach usually includes immediate invasive management, including large-bore chest tube insertion and video-assisted thoracoscopic surgery. 


\section{Case Reports in Acute Medicine}

Pradana: Spontaneous Tuberculosis-Associated Tension Pneumothorax

However, in clinical settings with limited resources, this cannot be done promptly. In this report, we present a case of spontaneous TB-associated tension pneumothorax in a young adult which resolved with needle decompression without chest tube drainage (CTD) insertion.

\section{Case Report}

A 32-year-old male from a rural part of Kendal in Indonesia presented to our emergency department with shortness of breath with a history of pulmonary TB for 5 years, and he was a smoker. He had symptoms of chronic productive cough of more than 2 weeks' duration along with significant weight loss, low-grade fever, and fatigue. The patient had a history of seeing multiple health facilities 3 months prior to his admission to our hospital. At least, he had visited 2 different hospitals and 1 public health center, and all of them had established a diagnosis of pulmonary TB. However, the patient showed low compliance with the treatment protocol and decided not to take the anti-tubercular medication for more than 2 months.

Our initial evaluation in the emergency department revealed slight tachycardia (heart rate $110 \mathrm{bpm}$ ), tachypnea (respiratory rate of $30 \times / \mathrm{min}$ ), blood pressure $100 / 80 \mathrm{~mm} \mathrm{Hg}$, and a sign of significant cyanosis. Pulse oximetry was $88 \%$ with room air, increasing to $95 \%$ on $100 \%$ oxygen $4 \mathrm{~L} / \mathrm{min}$ via nasal cannula. Physical examination revealed significantly decreased breath sounds on the left hemithorax, shifting the heart sounds to the right hemithorax. Chest X-ray was obtained and showed collapse of the left lung with shifting of the heart and mediastinum to the opposite hemithorax and a prominent fibrotic lesion in the right hemithorax (Fig. 1). We used the Light index to estimate pneumothorax size [3]. On admission, chest X-ray showed prominent left-sided pneumothorax with a Light index of $85.8 \%$. The patient was admitted to the level 0 infectious ward care for close monitoring with intravenous (IV) drip of aminophylline, ciprofloxacin IV $200 \mathrm{mg}$ b.i.d., methylprednisolone IV $62.5 \mathrm{mg}$ b.i.d., and $7-8 \mathrm{~L} / \mathrm{min} 100 \%$ oxygen via a nonrebreathing mask, without any significant intervention. Laboratory tests were obtained: WBC was $25,870 / \mathrm{mm}^{3}$, with neutrophils $89 \%$, platelet count $611,000 / \mathrm{mm}^{3}$, and smear-positive TB. Therefore, anti-tubercular treatment was started again according to the National TB Program [4].

Twenty-four hours after admission, the patient developed significant deterioration with cardiovascular compromise (blood pressure 129/89 mm Hg, heart rate $141 \mathrm{bpm}$, decreasing level of consciousness, $\mathrm{SpO}_{2} 84 \%$, cold extremities). Immediate needle decompression with an IV catheter of $14 \mathrm{G}$ in the left hemithorax was conducted. However, the patient and family refused CTD insertion due to financial constraints. The physician decided to attach the IV catheter for $48 \mathrm{~h}$ after symptoms of the patient were relieved drastically. A second chest X-ray showed significant resolution of left lung collapse with Light index of 59.6\% (Fig. 2). Subsequently, the patient was discharged home on TB treatment at day 3 with the next follow-up appointment as an outpatient 5 days after discharge.

\section{Discussion/Conclusion}

SSP is a pneumothorax that occurs in association with underlying lung disease, such as chronic obstructive pulmonary disease (COPD) and pulmonary TB. The incidence of SSP in pulmonary TB ranges between 1.3 and 5\% [2]. SSP that does not receive prompt intervention may progress to tension pneumothorax, which is a life-threatening condition. Significant risk factors for the development of tension pneumothorax in pulmonary TB are co-infection, 


\section{Case Reports in Acute Medicine}

Pradana: Spontaneous Tuberculosis-Associated Tension Pneumothorax

advanced TB (i.e., fibrotic adhesion and the size of bullae), and smoking [5]. Our patient had several conditions that triggered tension pneumothorax rapidly, such as possibly coinfections as suggested by prominent leukocytosis and fibrotic adhesion in the right hemithorax, smoking, and the current treatment status ("default" status). In this case, ciprofloxacin IV and methylprednisolone IV were given due to possibly mixed infections as shown by laboratory results (significant leukocytosis and predominant segmented neutrophilia).

The pathogenesis of spontaneous tension pneumothorax in pulmonary TB includes necrosis of pleura and pleural-pulmonary fibrotic adhesion, which possibly allows air leakage to the pleural cavity and is termed pleural porosity [6]. The management of tension pneumothorax obviously requires immediate needle decompression followed by CTD insertion. In our case, the patient refused CTD insertion due to financial constraints. The physician decided to attach the IV catheter for $48 \mathrm{~h}$. The patient had started to show significant clinical improvement immediately after needle decompression using a 14-G IV catheter with an anterior approach in the left hemithorax (Fig. 2). The drainage was not done on admission because the pulmonologist was not readily available for the chest tube thoracostomy backup procedure. Therefore, the pulmonologist only suggested a watchful observation in the infectious ward.

The use of a 14-G needle in emergency treatment in tension pneumothorax is supported by the Advanced Trauma Life Support guideline [7]. However, several studies did not support using a 14-G needle and suggested a longer needle with a minimum of $6.44 \mathrm{~cm}$ length [8-10]. In our case, needle decompression only, without further CTD insertion, showed $26.2 \%$ reduction in pneumothorax size.

Our case was unique since the patient had an advanced pulmonary TB with "doctor-shopping" habit, delayed significant intervention during admission, and refused the CTD insertion procedure.

Spontaneous TB-associated tension pneumothorax is a life-threatening condition and requires early recognition and prompt intervention to decrease the mortality burden.

\section{Acknowledgement}

The author thanks Dr. Aslani Therestiana Sari for the professional advice on manuscript drafting.

\section{Statement of Ethics}

The author has no ethical conflicts to disclose. A written informed consent was obtained from the patient.

\section{Disclosure Statement}

The author has no conflicts of interest to declare.

\section{Funding Sources}

The author did not receive any financial support. 


\section{Case Reports in Acute Medicine}

\section{References}

1 Shamaei M, Tabarsi P, Pojhan S, Ghorbani L, Baghaei P, Marjani M, et al. Tuberculosis-associated secondary pneumothorax: a retrospective study of 53 patients. Respir Care. 2011 Mar;56(3):298-302.

2 Aktoğu S, Yorgancioglu A, Cirak K, Köse T, Dereli SM. Clinical spectrum of pulmonary and pleural tuberculosis: a report of 5,480 cases. Eur Respir J. 1996 Oct;9(10):2031-5.

3 Salazar AJ, Aguirre DA, Ocampo J, Camacho JC, Díaz XA. Evaluation of three pneumothorax size quantification methods on digitized chest X-ray films using medical-grade grayscale and consumer-grade color displays. Digit Imaging. 2014 Apr;27(2):280-6.

4 Ministry of Health Republic of Indonesia. Regulation of the Minister of Health Number 67 Year 2016 on Tuberculosis Control. Indonesia; 2016. p. 1-163.

5 Yoon JS, Choi SY, Suh JH, Jeong JY, Lee BY, Park YG, et al. Tension pneumothorax, is it a really life-threatening condition? J Cardiothorac Surg. 2013 Oct;8(1):197.

6 Noppen M, De Keukeleire T. Pneumothorax. Respiration. 2008;76(2):121-7.

7 American College of Surgeons. Advanced Trauma Life Support: Student Course Manual. 10th ed. Rotondo MF, Fildes J, editors. Chicago: American College of Surgeons; 2018. p. 1-355.

8 Powers WF, Clancy TV, Adams A, West TC, Kotwall CA, Hope WW. Proper catheter selection for needle thoracostomy: a height and weight-based criteria. Injury. 2014 Jan;45(1):107-11.

9 Aho JM, Thiels CA, El Khatib MM, Ubl DS, Laan DV, Berns KS, et al. Needle thoracostomy: clinical effectiveness is improved using a longer angiocatheter. J Trauma Acute Care Surg. 2016 Feb;80(2):272-7.

10 Clemency BM, Tanski CT, Rosenberg M, May PR, Consiglio JD, Lindstrom HA. Sufficient Catheter Length for Pneumothorax Needle Decompression: A Meta-Analysis. Prehosp Disaster Med. 2015 Jun;30(3):249-53.

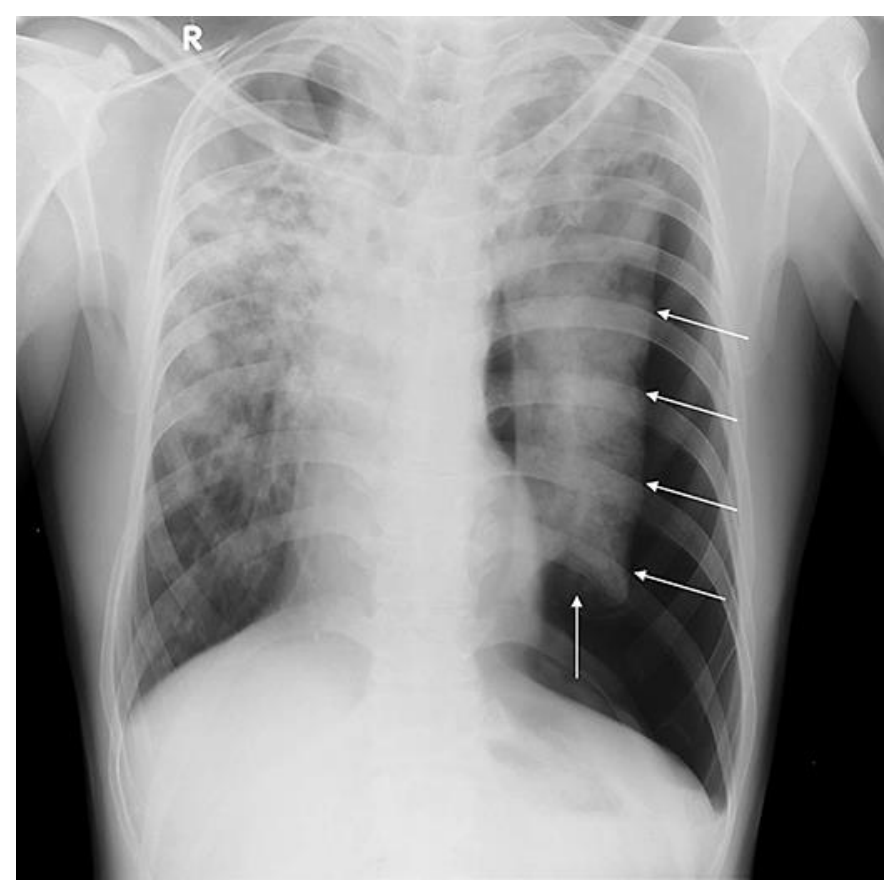

Fig. 1. On admission, chest X-ray showed tension pneumothorax and mediastinum shifting to the right hemithorax with a light index of $85.8 \%$. 
Case Reports in Acute Medicine
Case Rep Acute Med 2020;3:35-39

DOI: $10.1159 / 000508530$

www.karger.com/cra

Pradana: Spontaneous Tuberculosis-Associated Tension Pneumothorax

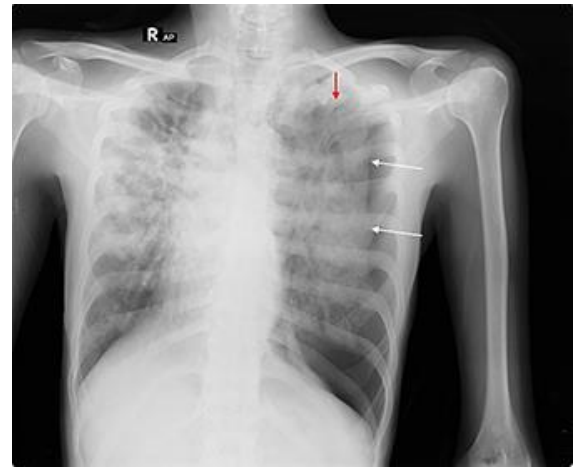

Fig. 2. Second chest X-ray $48 \mathrm{~h}$ after persistent needle decompression. Red arrow: needle decompression placement in the second intercostal space to the left midclavicular line. Light index was $59.6 \%$. 